\title{
VARIABILIDADE GENÉTICA ASSOCIADA À GERMINAÇÃO E VIGOR DE SEMENTES DE LINHAGENS DE FEIJOEIRO COMUM
}

\author{
Genetic variability associated with germination and seed vigor of common bean lines
}

\author{
Lucas Gontijo Silva Maia', Camila Andrade Silva², Magno Antonio Patto Ramalho, Ângela de Fátima Barbosa Abreu ${ }^{3}$
}

\section{RESUMO}

Objetivou-se, com este trabalho estimar a variabilidade genética para os caracteres relacionados com a velocidade de germinação e a capacidade das plantas em cobrir rapidamente o solo. Foram utilizadas sementes de 94 linhagens do banco de germoplasma de feijão (Phaseolus vulgaris L.) da Universidade Federal de Lavras, que diferiam em vários caracteres, tais como, cor, tamanho e formato das sementes. Foram realizados dois experimentos para avaliação das linhagens. O primeiro foi aos 120 dias e o segundo aos 360 dias após o início do armazenamento (em temperatura e umidade ambientes e sob baixa luminosidade). Foram obtidos as porcentagens de germinação $(\% \mathrm{G})$, o índice de velocidade de emergência (IVE) e a matéria seca (MS). As variáveis foram padronizadas e obtido o somatório do IVE + MS. Foram obtidas as correlações fenotípica, genética e ambiental entre todos os caracteres e estimaram-se o ganho esperado com a seleção e a resposta correlacionada. Tanto a \% G, quanto o IVE tiveram seus valores reduzidos na avaliação aos 360 dias após o armazenamento das sementes, em comparação com a avaliação realizada aos 120 dias. Foi possível obter ganho com a seleção, para maiores \%G, IVE e MS. O maior ganho foi obtido no primeiro experimento. Entre as linhagens avaliadas há variabilidade suficiente para se proceder à seleção com relação à germinação e emergência. As linhagens JALO EEP 558, PI-103 e CVII 39-24 foram identificadas como as melhores em relação à germinação e emergência e as linhagens RP-2, BP-34 e ESAL 569 foram as que apresentaram menor vigor.

Termos para indexação: Feijão, correlação, ganhos com a seleção, emergência, armazenamento.

\begin{abstract}
The objective of this study was to estimate the genetic variability for characters related with the germination rate and the capacity of the plants to occupy the ground quickly. Ninety four lines from the common bean (Phaseolus vulgaris L.) germoplasm from the Universidade Federal de Lavras, differing in several characters as color, size and shape of the seeds were used. Two experiments were carried out to evaluate the bean lines. The first was conducted at 120 days and the second 360 days after the beginning of storage (room temperature and humidity and under low light). Percentage of germination (\%G), emergency speed rate (ESR) and dry matter (DM) were obtained. The variables were standardized and obtained the sum of the ESR + DM. Phenotypic, genetic and environmental correlations between all the characters were obtained and the expected gain was estimated with the selection and correlated response. Both the G\% and ESR presented reduced levels in the evaluation at 360 days after seed storage in comparison with the evaluation at 120 days. It was possible to obtain the gain with the selection, for higher \%G, ESR and DM. The higher gain was obtained in the first experiment. Among the lines evaluated, there are genetic sufficient variability to proceed the selection for germination and emergence. The lines JALO EEP 558, PI-103 and CVII 39-24 were identified as the best for germination and emergence and the lines RP-2, BP-34 and ESAL 569 were those with smaller vigor.
\end{abstract}

Index terms: Beans, correlation, selection gain, emergency, storage.

(Recebido em 9 de fevereiro de 2010 e aprovado em 11 de novembro de 2010)

\section{INTRODUÇÃO}

Os agricultores têm procurado por cultivares de feijão que apresentem rápida germinação e elevado vigor. Quando isso ocorre, as plantas cobrem rapidamente o solo, diminuindo a chance da ocorrência de plantas daninhas e promovendo a formação homogênea do estande. A desuniformidade e a redução do estande podem conduzir não só à redução na produtividade de grãos como também acentuar problemas com plantas invasoras, como já mencionado. A desuniformidade da cultura é prejudicial em diversos estágios fenológicos (inclusive maturação), interferindo na qualidade do produto e nas características da planta relacionadas à eficiência da colheita.

A identificação de cultivares e ou linhagens de feijão que sejam de mais rápida germinação e emergência é uma das estratégias para o melhor estande e rápida cobertura do solo. Já existem evidências de que há variação para esses caracteres. Avaliando 101 linhagens de feijão vagem, Emygdio et al. (2000) verificaram que há variabilidade para o caráter. Porém as cultivares comerciais não estavam entre as de maior velocidade de germinação e emergência.

1 Universidade Federal de Lavras/UFLA - Departamento de Biologia/DBI - Lavras, MG

2Universidade Federal de Lavras/UFLA - Departamento de Biologia/DBI - Cx. P. 3037 - 37200-000 - Lavras, MG - camilaagro01@yahoo.com.br

${ }^{3}$ Empresa Brasileira de Pesquisa Agropecuária/Embrapa - Arroz e Feijão - Santo Antônio de Goiás/GO 
Informações sobre variabilidade para germinação e emergência ainda não foram obtidas para as principais linhagens disponíveis no mercado de feijão comum. Do exposto, realizouse o presente trabalho com o objetivo de verificar se há variabilidade genética para os caracteres relacionados à germinação e à emergência entre linhagens de feijão do banco de germoplasma da UFLA. Objetivou-se também verificar se estas propriedades genéticas variam com a idade das sementes.

\section{MATERIAL E MÉTODOS}

Os experimentos foram conduzidos na área experimental, localizada no Departamento de Biologia, da Universidade Federal de Lavras (UFLA), situada aos 918 metros de altitude, $21^{\circ} 14^{\prime} \mathrm{S}$ de latitude e $45^{\circ} 00^{\prime} \mathrm{W}$ de longitude, no período de outubro de 2008 a abril de 2009.

Foram utilizadas sementes de 94 linhagens do banco de germoplasma de feijão da Universidade Federal de Lavras, diferindo-se em vários caracteres tais como, cor, tamanho e formato das sementes. As linhagens foram multiplicadas a campo, durante a safra das águas do ano de 2007-2008, para que todas as sementes apresentassem a mesma idade fisiológica. Posteriormente, as sementes foram selecionadas manualmente com o intuito de eliminar aquelas com o tegumento defeituoso e com tamanhos discrepantes. As sementes foram armazenadas em temperatura e umidade ambientes e sob baixa luminosidade até o momento da utilização nos experimentos.
O primeiro experimento foi realizado aos 120 dias após o início do armazenamento, em condições normais de temperatura e umidade ambiente. O delineamento experimental utilizado foi o de blocos casualizados com quatro repetições e parcela constituída de uma linha de um metro com 24 sementes/metro. A semeadura foi realizada em canteiro, em casa de vegetação. Cuidou-se ao máximo para que as sementes fossem colocadas à mesma profundidade, de três centímetros, igualmente espaçadas e recebessem a mesma quantidade de água diária, de 3,75 mm, referente aos 30 minutos de irrigação por dia. O segundo experimento foi realizado, aos 360 dias após o início do armazenamento, nos mesmos moldes do primeiro experimento. Os dados referentes às condições climáticas (umidade relativa, temperatura média e precipitação) durante a condução dos experimentos são apresentados nas Figuras 1 e 2.

Procedeu-se às contagens das sementes germinadas diariamente. Procurou-se efetuar as contagens, no mesmo horário, a partir do aparecimento das primeiras plântulas. Esse procedimento ocorreu entre o quarto e o décimo quinto dia após a semeadura. Foram consideradas como germinadas as plântulas que apresentavam as folhas cotiledonares totalmente abertas.

No décimo quinto dia após a semeadura, as plantas foram cortadas na região do "colo" e secas em uma estufa de fluxo forçado a $65-67^{\circ} \mathrm{C}$ por 48 horas. Após esse período, a matéria seca foi obtida em gramas por parcela.

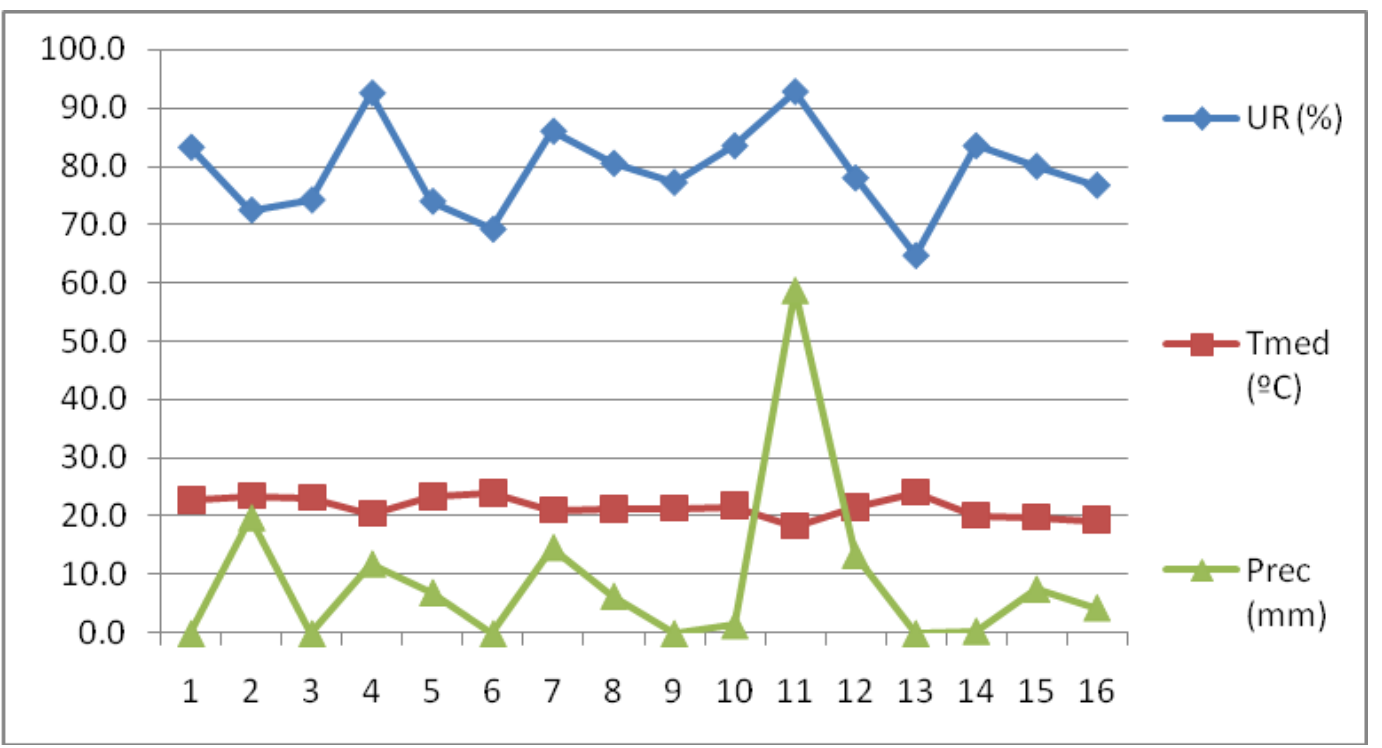

Figura 1 - Dados referentes a umidade relativa, precipitação pluvial e temperatura média, no período de realização do primeiro experimento. 


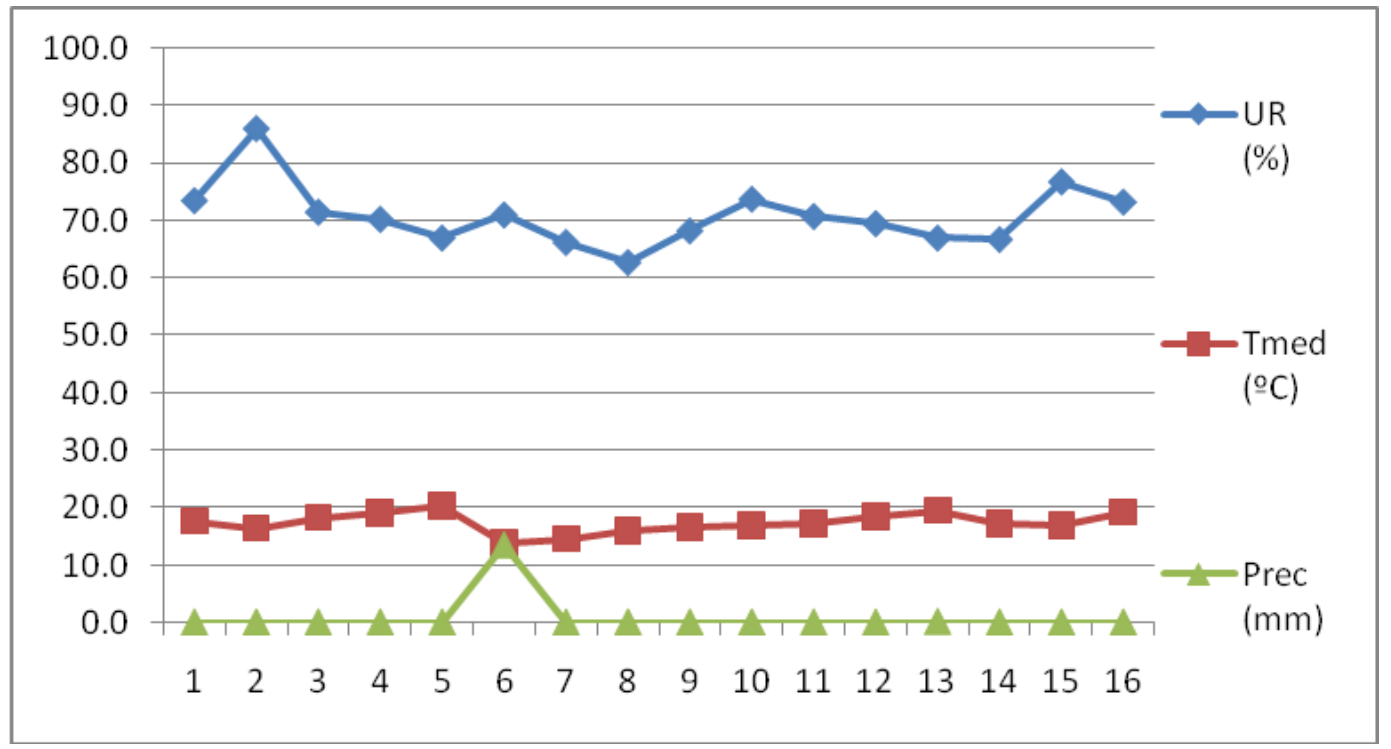

Figura 2 - Dados referentes a umidade relativa, precipitação pluvial e temperatura média, no período de realização do segundo experimento.

A partir dos dados experimentais, foram obtidos: A porcentagem de germinação $(\% \mathrm{G})$ pelo seguinte estimador, \%G= (Número de sementes germinadas $\mathrm{x} 100) /$ Número de sementes semeadas; em que o número de sementes germinadas foi computado no décimo quinto dia após a semeadura; o índice de velocidade de emergência (IVE), estimado segundo a metodologia proposta por Maguire (1962) pela expressão simplificada por Wang (2004): IVE $=\sum(G t / T t)$, sendo que: Gt é o número de plantas contadas como germinadas no dia da contagem; Tt é o dia da contagem.

Visando à detecção de uma estimativa que envolvesse a matéria seca e os caracteres de germinação, foi necessário padronizar as variáveis. A variável padronizada foi obtida pelo seguinte estimador (Ferreira, 2008): $Z=(x-m) / s$, em que x é a média do caráter considerado da linhagem i; $\mathrm{m}$ é a média de todas as linhagens e s é o desvio-padrão entre médias das linhagens. Como a variável padronizada assume valores negativos e positivos, foi adicionada uma constante a fim de que todos os dados fossem positivos. Como a correlação entre a porcentagem de germinação e a velocidade de emergência é normalmente alta, no somatório de padronização das variáveis considerou-se apenas o $\sum=I V E+M S$ (Schuch et al., 2000; Siqueira et al., 2001; Kolchinski et al., 2005).

Os dados obtidos em cada época foram submetidos à análise de variância individual e posteriormente à análise conjunta. $\mathrm{O}$ modelo estatístico adotado, considerando os efeitos de linhagens como aleatórios e os de épocas e média como fixos, foi o seguinte: $Y_{i j k}=m+p_{i}+b_{j(k)}+a_{k}+(p a)_{i k}+\bar{e}_{j(i k)}$, em que: $Y_{i j k}$ : valor observado na parcela que recebeu a linhagem $i$, na repetição $j$, na época $k ; m$ : média geral do experimento; $\rho_{i}$ : efeito da linhagem $i$, sendo $i=1,2, \ldots, 94 ; b_{j(k)}$ : efeito da repetição $j$, dentro da época $k$, sendo $j=1,2,3$ e 4; $a_{k}$ : efeito da época $k$, sendo $k=1$ e $2 ;(p a)_{i k}$ : efeito da interação linhagem $i$ e época $k ; \bar{e}_{j(i k)}$ : erro experimental médio. Os erros são independentes e normalmente distribuídos com média zero e variância $\sigma_{\mathrm{e}}^{2}$.

A partir das esperanças do quadrado médio (QM), foram estimadas as herdabilidades para a matéria seca e índice Z. Pelas expressões apresentadas por Knapp et al. (1985), com confiança de $1-\alpha=0,95$, foram obtidos os limites inferiores (LI) e superiores (LS) das estimativas de herdabilidade $\left.\left(h^{2}\right): L I=\left\{1-\left[Q_{1} / Q_{2}\right) x F_{1-\alpha}: g l 1, g l 2\right]^{-1}\right\}$; $L S=\left\{1-\left\{\left(Q_{1} / Q_{2}\right) x F_{\alpha / 2}: g l, g l 2\right]^{-1}\right\}$, em que: $\mathrm{F}_{\alpha / 2} \mathrm{eF}_{1-\alpha / 2}$ : valores tabelados da distribuição de $\mathrm{F}$, com $\mathrm{gl}_{1}$ e $\mathrm{gl}_{2}$ graus de liberdade, sendo $\alpha=0,05 ; \mathrm{gl}_{1}$ e $\mathrm{gl}_{2}$ : graus de liberdade associados ao QM de linhagens e ao QM do erro, respectivamente; $\mathrm{Q}_{1}$ e $\mathrm{Q}_{2}$ : $\mathrm{QM}$ de linhagens e $\mathrm{QM}$ do erro, respectivamente.

Foram estimadas as correlações fenotípica, genética e ambiental entre as variáveis. As análises foram efetuadas no software GENES (Cruz, 2006).

Estimou-se o ganho esperado com a seleção (GS) considerando as cinco melhores linhagens. A expressão 
utilizada foi: $G S=d s x h^{2}$, em que: ds é o diferencial de seleção, ou seja, a diferença entre a média das linhagens selecionadas e a média geral de todas as linhagens; $h^{2}$ é a herdabilidade do caráter. A resposta correlacionada (RC) no caráter y (IVE) pela seleção efetuada no caráter $\mathrm{x}\left(\sum Z\right)$ foi obtida pela seguinte expressão: $R C_{y(x)}=d s_{y(x)} \cdot h_{y}{ }^{2}$, em que: ds ${ }_{y(x)}$ é o diferencial de seleção indireto, que é obtido em função da média das linhagens selecionadas a partir da seleção direta; $h^{2}$ é a herdabilidade do caráter submetido à seleção indireta (Cruz et al., 2004).

\section{RESULTADOS E DISCUSSÃO}

A fonte de variação linhagens, na análise conjunta, foi significativa $(\mathrm{P} \leq 0,01)$ para matéria seca e somatório das variáveis IVE + MS padronizada ( $\sum z$ ). Já a interação linhagens $\mathrm{x}$ épocas foi significativa $(\mathrm{P} \leq 0,01)$ para todas as variáveis analisadas, exceto para matéria seca. Vale salientar que o quadrado médio do efeito de época para o $\sum z$ é nulo, pois a padronização foi realizada por época e, portanto a média é igual nas duas situações (Tabela 1). Para a matéria seca, o valor da herdabilidade foi de elevada magnitude (81.7\%), indicando a possibilidade de sucesso com a seleção.

$\mathrm{Na}$ avaliação realizada aos 120 dias após a colheita, a porcentagem de germinação foi de 96,8\% e o IVE de 14,2. Já na segunda avaliação, ocorreu redução de 19,4\% para germinação e de 18,3 para IVE. Essa redução nos valores máximos de IVE com o tempo de armazenamento das sementes está de acordo com os resultados apresentados por Bragantini (2005), em que foi relatado que, após os três primeiros meses de armazenamento, as cultivares de feijão apresentaram perda no vigor. Botelho et al. (2010) também relataram que o IVE diminui ao longo do desenvolvimento das plantas de feijão, causando perda de vigor. É importante ressaltar que quanto maior o valor de IVE, maior será a velocidade de germinação (Maguire, 1962). Isso já era esperado, uma vez que, com o passar do tempo, a semente vai perdendo a viabilidade, devido à deterioração. Esta, teoricamente, se inicia na maturação fisiológica, no entanto, esta deterioração é detectada com maior frequência durante o armazenamento. O declínio do potencial fisiológico com o passar do tempo não se restringe à diminuição da capacidade de germinação, que vai ficando mais lenta, assim como se acentua a sensibilidade à adversidades ambientais, caracterizando a queda do vigor (Marcos Filho, 2005).

A partir das estimativas de correlação (Tabela 2), verifica-se que, aos 120 dias, foram todas de pequena magnitude e não significativas. Na avaliação aos 360 dias, a correlação genética foi alta e positiva entre os caracteres \%G e IVE. A correlação é dependente da variabilidade existente entre os caracteres. Aos 360 dias, a variabilidade genética para os caracteres considerados acentuou-se em relação à observada aos 120 dias (Figura 3). Esse fato contribuiu para estimativas de correlação de maior magnitude nos resultados obtidos com as sementes mais velhas. A existência de correlação também é um indicativo de que, no controle genético dos dois caracteres, existem genes pleiotrópicos e/ou ligados (Falconer \& Mackay, 1996).

Tabela 1 - Resumo da análise de variância conjunta para porcentagem de germinação (\%G), índice de velocidade de emergência (IVE), matéria seca (MS em g/parcela) e para o índice Z (IVE+MS).

\begin{tabular}{lrcccc}
\hline \multirow{2}{*}{ FV } & \multicolumn{5}{c}{ Quadrado Médio (QM) } \\
\cline { 2 - 6 } & GL & $\% \mathrm{G}$ & IVE & MS & Z(IVE+MS) \\
\hline Linhagens & 93 & 116,89 & 43,82 & $2,40 *$ & $6,00 *$ \\
Época & 1 & $66325,14^{*}$ & $1270,67 *$ & 1,14 & 0,00 \\
Linhagens x Épocas & 93 & $117,53^{*}$ & $46,20 *$ & 0,44 & $3,99 *$ \\
Erro & 561 & 59,22 & 2,08 & 0,43 & 1,30 \\
\hline $\mathrm{CV}(\%)$ & & 8,80 & 11,17 & 7,25 & 19,08 \\
\hline $\mathrm{h}^{2}(\%)$ & - & - & 81,7 & 33,5 \\
$\mathrm{LI}$ & & - & - & 75,0 & 22,1 \\
LS & & - & - & 87,0 & 40,3 \\
\hline Médias aos 120 dias & & 96,8 & 14,2 & 10,9 & 6,0 \\
Médias aos 360 dias & & 78,0 & 11,6 & 10,8 & 6,0 \\
Médias conjunta & & 87,4 & 12,9 & 10,9 & 6,0 \\
\hline
\end{tabular}

*significativo pelo teste $\mathrm{F}$ ao nível de $1 \%$ de probabilidade. 
Tabela 2 -Estimativas de correlação fenotípica $\left(\mathrm{r}_{\mathrm{F}}\right)$, genética $\left(\mathrm{r}_{\mathrm{G}}\right)$ e ambiental $\left(\mathrm{r}_{\mathrm{A}}\right)$ entre Índice de Velocidade e Emergência (IVE) e Germinação (\%G), entre Índice de Velocidade e Emergência (IVE) e Matéria Seca (MS) e entre Germinação (\%G) e Matéria Seca (MS).

\begin{tabular}{lcccccc}
\hline \multirow{2}{*}{ Caracteres } & \multicolumn{2}{c}{$\mathrm{r}_{\mathrm{F}}$} & \multicolumn{3}{c}{$\mathrm{r}_{\mathrm{G}}$} & $\mathrm{r}_{\mathrm{A}}$ \\
\cline { 2 - 7 } & 120 dias & 360 dias & 120 dias & 360 dias & 120 dias & 360 dias \\
\hline IVE e \%G & $-0,02$ & 0,93 & 0,07 & 0,92 & 0,03 & 0,89 \\
IVE e MS & $-0,22$ & 0,35 & $-0,24$ & 0,32 & 0,03 & 0,41 \\
$\%$ G e MS & 0,16 & 0,48 & 0,38 & 0,54 & $-0,02$ & 0,43 \\
\hline
\end{tabular}

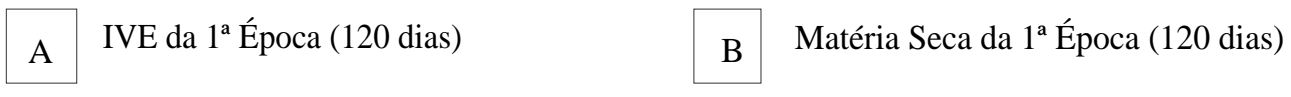

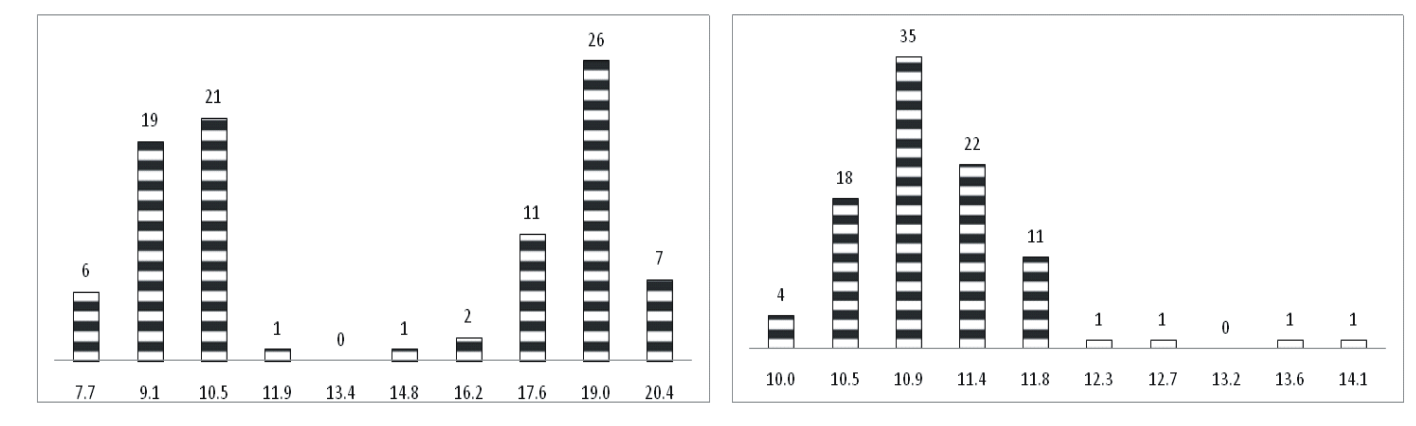

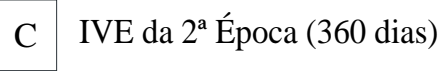

D Matéria Seca da $2^{a}$ Época (360 dias)
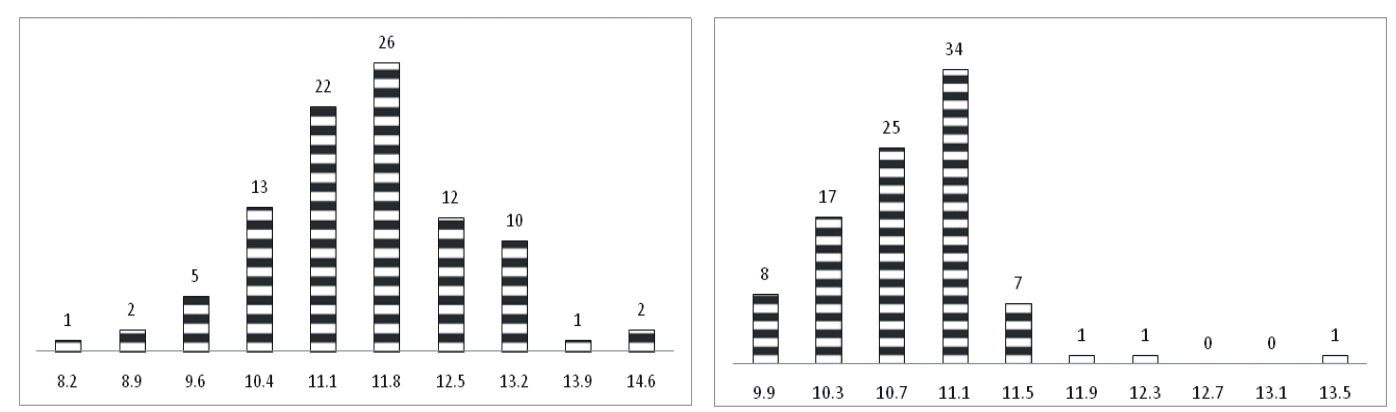

E IVE Conjunta

F $\quad$ Matéria Seca Conjunta

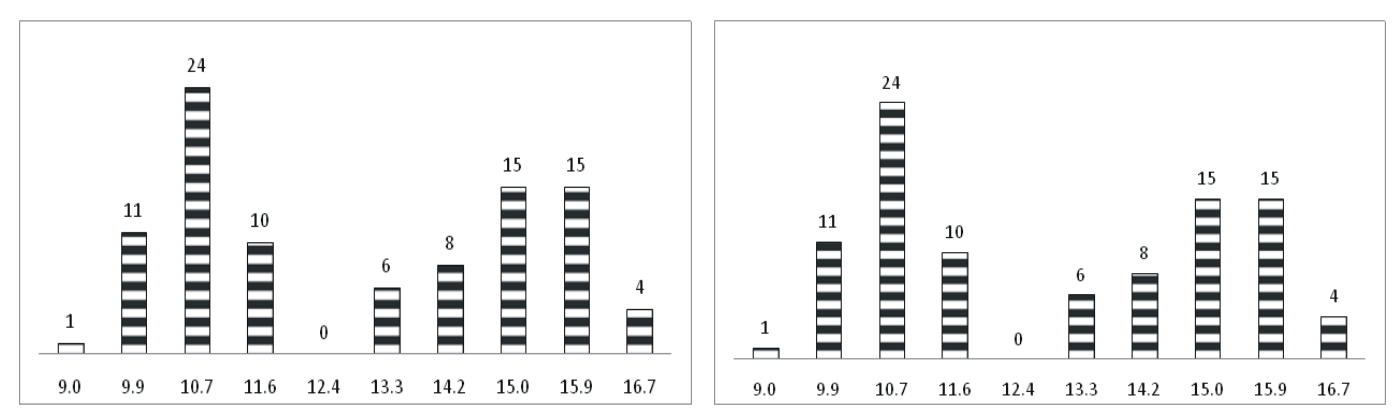

Figura 3 - Gráficos de distribuição de frequência das variáveis IVE (época 1, 2 e média) e MS (época 1, 2 e média).

Ciênc. agrotec., Lavras, v. 35, n. 2, p. 361-367, mar./abr., 2011 
Os gráficos de distribuição de frequência apresentados na Figura 3 comprovam a existência de variabilidade genética entre as linhagens, tanto para o caráter IVE (1A, 1C e 1E), quanto para matéria seca (1B, 1D e 1F). Para MS também foi observada variação na distribuição de frequência entre as linhagens, porém, nota-se que a distribuição é assimétrica, com concentração das primeiras classes. A linhagem que obteve o maior acúmulo de MS foi o JALO EEP 558, que apresenta características de grão do grupo manteigão (grãos amarelos e grandes) (Pereira Júnior et al., 2008). $\mathrm{O}$ fato de ter grãos grandes implica folhas cotiledonares também grandes e assim é explicada a maior massa seca nessa linhagem. A maioria das linhagens avaliadas são do grupo mesoamericano, com peso de 100 sementes de aproximadamente $25 \mathrm{~g}$. Sendo assim concentraram-se, nas primeiras classes, aquelas com sementes menores e que não diferem na MS nos primeiros dias após a germinação.

Estimou-se o ganho esperado com a seleção, considerando o somatório MS + IVE padronizados, valor de Z. Ao contrário do que era esperado, a maior estimativa do ganho foi obtida aos 120 dias, de $31 \%$ e aos 360 dias de $20 \%$ em relação à média geral. Em princípio, esses resultados evidenciam a possibilidade de se ter sucesso com a seleção para a rapidez de germinação associada ao maior desenvolvimento vegetativo inicial. Contudo, o sucesso será maior se a seleção for efetuada aos 120 dias.

A estimativa da resposta correlacionada no caráter IVE pela seleção obtida no índice Z foi de $12 \%$ aos 120 dias e de $8.5 \%$ aos 360 dias. Esse resultado era esperado, pois o IVE participa da estimativa do somatório de Z. A partir dos resultados obtidos, foi realizada a seleção de linhagens contrastantes para os caracteres avaliados. As linhagens JALO EEP 558, PI-103 e CVII 39-24 foram selecionadas como as melhores, por apresentarem maiores valores $\mathrm{do} \sum z \mathrm{e}$ as linhagens RP-2, BP-34 e ESAL 569 foram as que apresentaram menores valores do $\sum z$. Essas linhagens poderão ser utilizadas em trabalhos futuros visando a estimar o controle genético desses caracteres.

\section{CONCLUSÕES}

Entre as linhagens avaliadas, há variabilidade suficiente para se proceder à seleção com relação à germinação e emergência.

O poder germinativo e a velocidade de emergência das sementes diminuíram com o tempo de armazenamento.

\section{REFERÊNCIAS BIBLIOGRÁFICAS}

BOTELHO, F.J.E.; GUIMARÃES, R.M.; OLIVEIRA, J.A.; EVANGELISTA, J.R.E.; ELOI, T.de A.; BALIZA, D.P.

Desempenho fisiológico de sementes de feijão colhidas em diferentes períodos do desenvolvimento. Ciência e Agrotecnologia, Lavras, vol.34, n.4, p.900-907, jul./ago., 2010 .

BRAGANTINI, C. Alguns aspectos do armazenamento de sementes e grãos de feijão. Santo Antônio de Goiás: Embrapa, 2005. (Documentos, 187).

CRUZ, C.D. Programa genes: estatística experimental e matrizes. Viçosa, MG: UFV, 2006. v.1, 285p.

CRUZ, C.D.; REGAZZI, A.J.; CARNEIRO, P.C.S. Modelos biométricos aplicados ao melhoramento genético. 3.ed. Viçosa, MG: UFV, 2004. v.1, 480p.

EMYGDIO, B.M.; LOBATO, L.A. de O.; ANTUNES, I.F.; SILVEIRA, E.P. Variabilidade genética para velocidade de germinação em sementes de feijão (Phaseolus vulgaris L.).

Pesquisa Agrupecuária Gaúcha, Porto Alegre, v.6, n.1, p.77-82, 2000.

FALCONER, D.S.; MACKAY, T.F.C. Introduction to quantitative genetics. 4.ed. New York: Longman, 1996. $464 p$.

FERREIRA, D.F. Estatística multivariada. Lavras: UFLA, 2008. 672p.

KNAPP, S.J.; STROUP, W.W.; ROSS, W.M. Exact confidence intervals for heritability on a progeny mean basis. Crop Science, Madison, v.25, p.192-194, 1985.

KOLCHINSKI, E.M.; SCHUCH, L.O.B.; PESKE, S.T.

Vigor de sementes e competição intra-específica em soja. Ciência Rural, Santa Maria, v.35, n.6, p.1248-1256, nov./ dez. 2005.

MAGUIRE, J.D. Speed of germination-aid in selection and evaluation for seedling emergence and vigor. Crop Science, Madison, v.2, n.1, p.176-177, 1962.

MARCOS FILHO, J.M. Fisiologia de sementes de plantas cultivadas. Piracicaba: FEALQ, 2005. 
PEREIRA JÚNIOR, T.J. de P.; VIEIRA, R.F.; TEIXEIRA, H.; COELHO, R.R.; CARNEIRO, J.E. de S.; ANDRADE, M.J.B. de; REZENDE, A.M. Informações técnicas para o cultivo do feijoeiro-comum na região central brasileira: 2007-2009. Viçosa, MG: EPAMIG, 2008.

SCHUCH, L.O.B.; NEDEL, J.L.; ASSIS, F.N.; MAIA, M.S. Emergência a campo e crescimento inicial de aveia preta em resposta ao vigor de sementes.

Revista Brasileira de Agrociência, Pelotas, v.6, n.2, p.97-101, 2000.
SIQUEIRA, J.L. de; KIKUTI, H.; GARCIA, J.C.;

MARINHO, J.T. de S. Emergência e vigor de sementes de feijoeiro em função de safras e períodos de armazenamento. Ciência e Agrotecnologia, Lavras, v.25, n.1, p.206-212, jan./fev. 2001.

WANG, Y.R.; YU, L.; NAN, Z.B.; LIU, Y.L. Vigor tests used to rank seed lot quality and predict field emeergenve in four forage species. seed physiology, production and tecnology. Crop Science, Madison, v.44, p.535-541, 2004. 